\title{
New Mothers and Media Use: Associations Between Blogging, Social Networking, and Maternal Well-Being
}

\author{
Brandon T. McDaniel \\ The Pennsylvania State University \\ Sarah M. Coyne \\ Brigham Young University - Provo \\ Erin K. Holmes \\ Brigham Young University - Provo, erin_holmes@byu.edu
}

Follow this and additional works at: https://scholarsarchive.byu.edu/facpub

Part of the Other Social and Behavioral Sciences Commons

\section{Original Publication Citation}

*McDaniel, B. T., Coyne, S. M., and Holmes, E. K. (2012). New mothers and media use:

Associations between blogging, social networking, and maternal wellbeing. Maternal and Child Health Journal, 16(7), 1509-1517.

\section{BYU ScholarsArchive Citation}

McDaniel, Brandon T.; Coyne, Sarah M.; and Holmes, Erin K., "New Mothers and Media Use: Associations Between Blogging, Social Networking, and Maternal Well-Being" (2011). Faculty Publications. 4770.

https://scholarsarchive.byu.edu/facpub/4770

This Peer-Reviewed Article is brought to you for free and open access by BYU ScholarsArchive. It has been accepted for inclusion in Faculty Publications by an authorized administrator of BYU ScholarsArchive. For more information, please contact ellen_amatangelo@byu.edu. 


\title{
New Mothers and Media Use: Associations Between Blogging, Social Networking, and Maternal Well-Being
}

\author{
Brandon T. McDaniel - Sarah M. Coyne • \\ Erin K. Holmes
}

Published online: 18 November 2011

(C) Springer Science+Business Media, LLC 2011

\begin{abstract}
Drawing on Bronfenbrenner's ecological theory and prior empirical research, the current study examines the way that blogging and social networking may impact feelings of connection and social support, which in turn could impact maternal well-being (e.g., marital functioning, parenting stress, and depression). One hundred and fifty-seven new mothers reported on their media use and various well-being variables. On average, mothers were 27 years old $(\mathrm{SD}=5.15)$ and infants were 7.90 months old $(\mathrm{SD}=5.21)$. All mothers had access to the Internet in their home. New mothers spent approximately 3 hours on the computer each day, with most of this time spent on the Internet. Findings suggested that frequency of blogging predicted feelings of connection to extended family and friends which then predicted perceptions of social support. This in turn predicted maternal well-being, as measured by marital satisfaction, couple conflict, parenting stress, and depression. In sum, blogging may improve new mothers' well-being, as they feel more connected to the world outside their home through the Internet.
\end{abstract}

Keywords Transition to parenthood - Maternal well-being $\cdot$ Media use $\cdot$ Blogging $\cdot$ Social networking

\footnotetext{
B. T. McDaniel ( $\square)$

Human Development and Family Studies, The Pennsylvania

State University, S 110 Henderson Bldg., University Park, PA 16802, USA

e-mail: bom5123@psu.edu
}

S. M. Coyne · E. K. Holmes

Brigham Young University, Provo, UT, USA

\section{Introduction}

The transition to parenthood is a long-term restructuring process that begins at pregnancy and continues for some time after the birth of the child [1]. Due to the substantial demands a newborn child poses to the family, the transition to parenthood is among the most stressful life events many individuals experience [2] and can be associated with a host of psychological, physical, and social problems for parents [2-5]. Successful employment of social, familial, and spousal resources is key to managing parenting stress and to transitioning well to parenthood [6].

Social support for new parents has been connected with better maternal health, relationship satisfaction, child outcomes, and parent-child interactions [7-9]. One way that new mothers may receive support to navigate and deal with their new responsibilities is through social connection offered via new forms of media [10]. There are mixed claims about the Internet's effect on mothers. Some claim that the Internet can help empower women through online communities and information exchange [11-14]. Yet, others claim that the Internet merely affirms norms of femininity and consumerism [15], which could negatively influence mothers' feelings of parenting stress, competency, and adjustment to the transition in general. Also, some studies find that high levels of Internet use may result in less time spent with others and increased loneliness [16], while other studies show no displacement of time with others [17]. Given these mixed results for overall time spent on the Internet, it is important to examine specific types of Internet use, such as blogging or social networking that may be associated with aspects of maternal well-being.

Blogging and social networking are relatively new forms of expression and connection for mothers. For example, "mommy blogs" have received great attention in 
the news media and are reportedly a very popular media form used by mothers to connect with the wider parenting community [18]. This may be particularly important for new mothers, as such women may feel isolated and tied down by a newborn's schedule. Whether new mothers create their own blogs or read established blogs, participation in blogging may provide such mothers both a distraction and a sense of connection with other mothers around the world, assuring them that they are not alone [19]. Similarly, social networking may provide a sense of connection for new mothers; such sites provide ample opportunity to connect with friends and family without ever leaving one's home.

Even with many mothers using the Internet on a day-today basis, Madge and O'Connor [20] point out that the use of the Internet by new mothers has not been adequately explored. Plantin and Daneback [21] also explain that many of the studies examining parents' media use have lacked theoretical frameworks, leaving many questions unanswered. Thus, it is important to use a strong theoretical framework to empirically examine whether blogging and social networking can actually facilitate social connection and support for new mothers.

Besides increasing feelings of connectivity for new mothers, participation in new media may also indirectly influence a mother's stress, which may impact her depression, marital quality, and family functioning [2, 2225]. Prior research has established that social support buffers parenting stresses [26-28]. Thus, in this paper we examine how participation in blogging and social networking may indirectly be associated with a number of maternal outcomes, including parenting stress, social support, marital conflict, marital satisfaction, and depression.

\section{Conceptual Framework}

Based on Bronfenbrenner's ecological theory, transition to parenthood researchers emphasize the interplay between individuals, families, and the larger social context [29]. Ecological theory assumes that individuals develop in a multitude of systemic contexts: the microsystem, mesosystem, exosystem, and macrosystem. The two systems most relevant to the role of media on motherhood are the microsystem, which encompasses the relationships and interactions a mother, her partner, and her child have with their immediate surroundings (e.g., the interactions they have at home), and the mesosystem, which represents the connection between the mother and the institutions with which she interacts (e.g., the connection between new media such as blogging or social networking sites and the mother). Thus, guided by this framework, mothers should be able to improve interactions within their microsystem (e.g., interactions with their partner and their child) if these microsystemic interactions are facilitated by their interaction with others in the mesosystem (e.g., relationships with others in their community through media institutions such as blogging and social networking sites). For example, mothers may be able to share successful personal experiences on a blog or social networking site and receive feedback from other parents that will reinforce perceptions of social support. Mothers may also learn through observation or vicarious experience as they read about others' experiences. All of this feedback via blogs and social networking sites may increase perceptions of social support and reduce a mother's stress, subsequently enhancing other aspects of her wellbeing, including increased positive perceptions of marital quality, decreased marital conflict, and decreased depressive symptoms.

\section{The Current Study}

The aim of the current study is to examine whether participation in blogging and social networking are associated with maternal well-being. We focus on first-time mothers who have recently transitioned to parenthood, a group that is arguably more at risk for feelings of isolation and parenting stress than more experienced parents. Based on Bronfenbrenner's ecological theory and other research concerning mothering and media use $[10,20,30]$, we present the following hypotheses:

H1: We hypothesize that new mothers will utilize the computer and Internet every day, with at least some of this time spent on social networking and blogging.

H2: We predict that the majority of new mothers will report reasons for blogging that align with perceptions of social support, such as maintaining contact with family and friends.

H3: As outlined in our conceptual framework, we were most interested in mothers' microsystems and mesosystems. Therefore, we hypothesize that media social supports, such as blogging and social networking, will be associated with new mothers' abilities to stay connected with others in their social network and with stronger perceptions of social support (mesosytem). We then hypothesize that social support will be negatively related to mycrosystemic processes including parenting stress, marital conflict, and maternal depression, and positively related with marital satisfaction. Decreased parenting stress is expected to be associated with decreased maternal depression and marital conflict. Marital conflict is expected to be negatively related to marital satisfaction. Figure 1 shows the hypothesized model. 
Fig. 1 Hypothesized model of media influence on maternal well-being

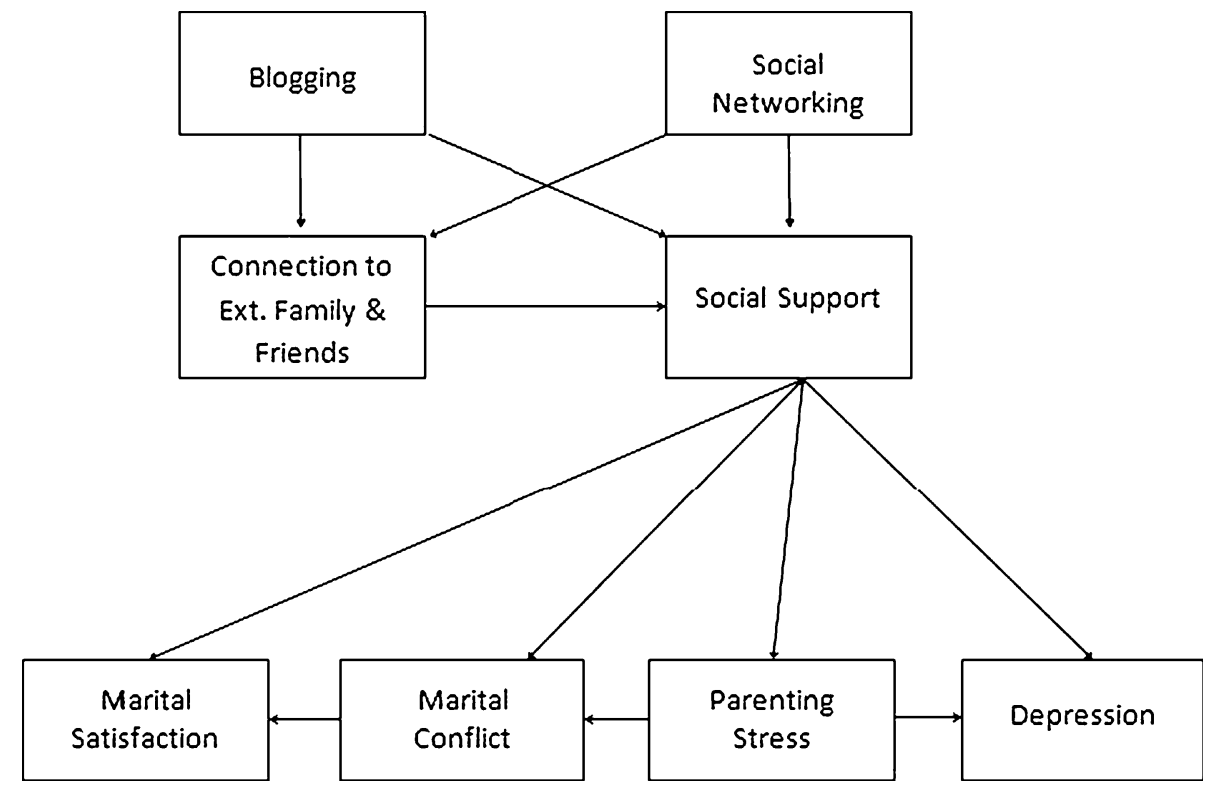

\section{Methods}

Procedure

New mothers were recruited through classroom announcements, emails, and contacts with local hospitals and birthing clinics. In order to qualify for inclusion in this study, mothers had to have a baby less than 18 months old which was their only and first child. Mothers who qualified were directed to the online survey. This research was conducted in accord with prevailing ethical principles as set forth by the American Psychological Association and was approved by the University Institutional Review Board (IRB).

\section{Participants}

One hundred and fifty-seven new mothers completed the study. On average, the mothers were 27 years old $(\mathrm{SD}=5.15)$, were in their first marriage, and had been married an average of 3.26 years $(\mathrm{SD}=2.15)$. Their infants were on average 7.90 months old $(\mathrm{SD}=5.21)$. Most of the mothers were White non-Hispanic, had graduated from college, and had a household income of less than $\$ 50,000$. About half of the mothers worked, with some of them working from home. The average number of hours worked in a week was $12.18(\mathrm{SD}=15.94)$. All mothers had a computer and the Internet in their home (see Table 1).

\section{Measures}

\section{Media Use and Daily Life}

Media use by new mothers was measured by asking them to enter the average number of hours they use various forms of media per day, such as using the computer, watching television, using a mobile phone, and listening to music. They were also asked to indicate how often they participate in these activities across a 5-point scale, ranging from 1 (never) to 3 (once every 2-3 weeks) to 5 (several times a week). Time spent on daily life tasks was also rated by mothers (e.g., housework, childcare tasks, and sleeping). All media use items were created specifically for this study and were pilot tested to ensure readability.

\section{Computer and Internet Use}

Although it is understood that mothers may also have access to the Internet via mobile phones, iPads, and other devices, mothers reported mainly on their computer and Internet use (e.g., "How frequently are you using the internet when on the computer?"). They also rated how often they engaged in ten specific activities while on the Internet, including "blogging", "social networking (e.g., Facebook, MySpace, etc.)", "checking email", "searching for and reading parenting information", "reading the news", "listening to music (e.g., Pandora, etc.)", "shopping (e.g., Amazon, Walmart, etc.)", "researching for a class or work", "chatting", and "watching TV/Movies". An "other" item was also included where mothers could write in additional ways that they used the Internet that were not already listed. These items were rated on a 5-point scale, ranging from 1 (never) to 5 (very often). Only blogging and social networking items were retained for the current study.

\section{Reasons for Blogging}

Mothers' reasons for blogging were assessed using a measure developed by Lenhart and Fox [31]. This measure 
Table 1 Sample characteristics

\begin{tabular}{|c|c|c|}
\hline Variable & Mean (or N) & $\mathrm{SD}($ or $\%)$ \\
\hline \multicolumn{3}{|l|}{ Household income } \\
\hline$<\$ 20,000$ & 47 & $30 \%$ \\
\hline$\$ 20,000-\$ 50,000$ & 46 & $29 \%$ \\
\hline$>\$ 50,000$ & 64 & $41 \%$ \\
\hline \multicolumn{3}{|l|}{ Ethnicity } \\
\hline White, non-Hispanic & 141 & $89 \%$ \\
\hline African American & 4 & $3 \%$ \\
\hline Hispanic American & 6 & $4 \%$ \\
\hline Other & 6 & $4 \%$ \\
\hline \multicolumn{3}{|l|}{ Education } \\
\hline College-graduate & 123 & $78 \%$ \\
\hline Some college & 31 & $20 \%$ \\
\hline High school graduate & 3 & $2 \%$ \\
\hline \multicolumn{3}{|l|}{ Employment } \\
\hline Currently working & 83 & $53 \%$ \\
\hline Working from home & 31 & $20 \%$ \\
\hline Hours working per week & 12.18 & 15.94 \\
\hline \multicolumn{3}{|l|}{ Mother } \\
\hline Age (in years) & 27.08 & 5.15 \\
\hline \multicolumn{3}{|l|}{ Child } \\
\hline Age (in months) & 7.90 & 5.21 \\
\hline \multicolumn{3}{|l|}{ Marriage } \\
\hline First marriage & 157 & $100 \%$ \\
\hline Length of marriage & 3.26 & 2.15 \\
\hline Computer with internet in home & 157 & $100 \%$ \\
\hline
\end{tabular}

Total $\mathrm{N}=157$

lists ten common reasons for blogging and asks the participant to rate whether each reason is a (1) major reason, (2) minor reason, or (3) not a reason that she blogs (Cronbach's $\alpha=.71$ ). Reasons include items such as to express yourself creatively, to document your personal experiences or share them with others, to stay in touch with friends and family, and to share practical knowledge or skills with others.

\section{Feelings of Connectedness}

Feelings of connection were assessed using the following two items which were rated across a 4-point scale ranging from 1 (very isolated) to 4 (very connected): (1) extended family and (2) friends (Cronbach's $\alpha=.70$ ). For the purposes of our analysis, a composite 'connection to extended family and friends' was created by summing the items and taking the mean.

\section{Social Support}

Social support was measured using the Relationships with Other People Scale [32, 33], an 11-item measure on which mothers rate their perceived availability of support over the past month. Each item is scored from 1 (none of the time) to 6 (all of the time). Higher scores represent greater perceived availability of support. Cronbach's $\alpha$ was .90 .

\section{Parenting Stress}

Mothers completed a 30-item, modified version of the 101-item Parenting Stress Index [34]. Each item is scored on a 5-point Likert-type scale ranging from 1 (strongly disagree) to 5 (strongly agree). Higher scores represent greater parenting stress (Cronbach's $\alpha=.83$ ).

\section{Marital Conflict}

To assess marital conflict, participants responded to eight common problems experienced in couple relationships in terms of how often each item is a problem in their relationship. Items were selected from the RELATE assessment battery [35], such as "Rearing children" and "Financial matters." Responses were based on a 5-point Likert scale ranging from 1 (never) to 5 (very often). In the present study, frequency of conflict had good internal consistency (Cronbach's $\alpha=.75$ ).

\section{Marital Satisfaction}

Marital satisfaction was assessed using the Quality of Marriage Index (QMI) [36]. The QMI is a six-item inventory that assesses marital satisfaction using broad items, such as "We have a good marriage." The respondent shows the degree of agreement with each of the five items on a scale of 1 (very strongly disagree) to 7 (very strongly agree). In the present study, the QMI had high internal consistency (Cronbach's $\alpha=.96$ ).

\section{Maternal Depression}

Mothers completed the CES-D, which is designed to measure maternal symptoms of depression [37]. Mothers rate how often they have felt 20 different symptoms during the past week. Each item is rated on a 4-point scale ranging from 0 (rarely or none of the time-less than 1 day) to 3 (most or all of the time-5 to 7 days) (Cronbach's $\alpha=.81)$.

\section{Results}

Descriptive Analyses: Mothers' Media Use

The most frequently used media item by mothers was the computer $(M=5.90, \mathrm{SD}=0.37)$, with mothers' rating 
themselves as using it every day. Interestingly, the amount of hours the computer was used per day $(M=3.12$, $\mathrm{SD}=2.50)$ came behind only childcare tasks $(M=8.72$, $\mathrm{SD}=4.06)(t(156)=-13.46, P<.001)$ and sleeping $(M=7.34, \mathrm{SD}=1.52) \quad(t(156)=-17.20, \quad P<.001)$. Also, mothers spent about 1 hour longer on the computer than on housework each day $(M=1.87, \mathrm{SD}=1.05)$ $(t \quad(156)=5.41, P<.001)$. Watching television $(M=$ 4.88, $\mathrm{SD}=1.58)$, listening to music $(M=4.78, \mathrm{SD}=$ $1.09)$, reading books $(M=4.75, \mathrm{SD}=1.29)$, and texting were also frequent $(M=4.59, \mathrm{SD}=1.85)$.

\section{Computer Use}

As mothers extensively used computers, it is key to examine what they were doing while on the computer. The results show that they most frequently were using the Internet. Mothers were on the Internet while on the computer almost 3 hours per day on average $(M=2.92$, $\mathrm{SD}=2.37$ ). In sum, they were on the Internet almost the entire time they were on the computer each day.

\section{Internet Use}

The next step was to examine what mothers were doing while on the Internet. While on the Internet, mothers utilized social networking sites fairly often $(M=3.78$, $\mathrm{SD}=1.25) \quad$ and blogged sometimes $\quad(M=3.30$, $\mathrm{SD}=1.22$ ). Although these mothers utilized social networking sites significantly more than blogging on average $(t(155)=4.21, P<.001)$, social networking and blogging both ranged from those that never used them to those who used them very often. There were no significant differences between mothers who blogged and those who did not on any demographic variables, whereas those who utilized social networking sites were younger $(M=26.73$, $\mathrm{SD}=4.97)$ than those who never used these sites $(M=30.00, \mathrm{SD}=5.67)(t(154)=2.24, P<.05)$.
Reasons for Blogging

Blogging was a fairly popular phenomenon in this study. Of 157 mothers, 111 read blogs at least sometimes (76\%), and 96 authored their own blogs (61\%). Those who authored blogs rated their reasons for blogging. The major reasons for blogging were to document personal experiences or share them with others $(89 \%)$ and to stay in touch with friends and family $(86 \%)$. This appears to support the hypothesized model of blogging linking with connection to others.

\section{Bivariate Correlations Between Study Variables}

Bivariate correlations between all main variables are presented in Table 2. All correlations were in the predicted directions, although some variables were related in unanticipated ways. For example, social networking was not associated with any outcome variable, while blogging related only to connection to extended family and friends and social support.

\section{Main Analysis}

\section{Analysis Plan}

Structural Equation Modeling (SEM) using maximum likelihood estimation in the Analysis of Moments Structure (AMOS) software [38] was conducted to test the fit of our hypothesized model to the data. SEM is a multivariate statistical analysis which allows scholars to test and refine complex theoretical models. SEM is preferred over regression as SEM uses maximum likelihood estimation. Maximum likelihood estimation minimizes bias (i.e., Type 1 error) in estimates, allows one to include multiple independent and dependent variables in the same analysis (which offers a better assessment of the overall strength and direction of effects), and offers basic confidence intervals and other assessments of goodness of fit for

Table 2 Zero-order correlations between independent and dependent variables and descriptive statistics

\begin{tabular}{|c|c|c|c|c|c|c|c|c|c|c|}
\hline & 1 & 2 & 3 & 4 & 5 & 6 & 7 & 8 & Mean & $\mathrm{SD}$ \\
\hline 1. Social networking & 1.00 & $.28 * * *$ & .12 & .07 & .08 & .01 & -.04 & -.01 & 3.78 & 1.26 \\
\hline 2. Blogging & & 1.00 & $.25 * *$ & $.18^{*}$ & -.10 & .10 & -.08 & .08 & 3.30 & 1.22 \\
\hline 3. Connection to extended family and friends & & & 1.00 & $.36 * * *$ & -.06 & .05 & .09 & -.09 & 3.29 & 0.51 \\
\hline 4. Social support & & & & 1.00 & $-.36 * * *$ & $.41 * * *$ & $-.19 *$ & $-.17 *$ & 58.61 & 6.36 \\
\hline 5. Frequency of conflict & & & & & 1.00 & $-.51 * * *$ & $.25 * *$ & $.20 *$ & 17.40 & 4.24 \\
\hline 6. Marital satisfaction & & & & & & 1.00 & .13 & -.14 & 27.71 & 3.19 \\
\hline 7. Parenting stress & & & & & & & 1.00 & $.26 * *$ & 83.12 & 8.01 \\
\hline 8. Depression & & & & & & & & 1 & 9.38 & 6.44 \\
\hline
\end{tabular}

$* P<.05 ; * * P<.01 ; * * *<<.001(\mathrm{~N}=146)$ 
hypothesis testing [39]. Goodness of fit indexes compare the observed covariances with the covariances predicted by the hypothesized model. Assessments of "goodness of fit" include the Chi-square $\left(\chi^{2}\right)$ test, the Root Mean Square Error of Approximation (RMSEA), and baseline comparison indexes such as the Tucker-Lewis Index (TLI) or Comparative Fit Index (CFI). $\chi^{2}$ examines whether or not there is a statistically significant difference between the model and the sample data and degrees of freedom. A non-significant $\chi^{2}$ statistic is preferable as it reflects "exact fit" between the hypothesized model and the data. The RMSEA reflects good model fit with a score of .06 or lower (the lower the better), while the TLI/CFI reflect good model fit with a score of .95 or higher (on a scale of $0-1)$ [40].

Building a sound structural equation model is often referred to in two steps: (1) building and refining the measurement model, and (2) testing and refining the structural model. While the measurement model allows one to account for measurement error, an important guideline in model building is that one must have at least 10 individuals per parameter to be estimated. Due to our sample size, we were unable to estimate both the structural and measurement models. Thus, we report only the structural model (for guidelines regarding sample size and parameter estimation in the measurement model, see Kline [41]). However, we emphasize that the benefits of maximum likelihood estimation and SEM as a multivariate statistical tool are still present in the building and testing of the structural model [39, 41].

\section{Results}

We tested a structural model of engagement in blogging and social networking as predictors of connection with family and friends and social support using maximum likelihood estimation in AMOS. These variables were then modeled as predictors of marital satisfaction, marital conflict, parenting stress, and depression. The hypothesized model did not meet acceptable criteria for good model fit [40] $\left(\chi^{2}(16)=24.20, P=.09 ;\right.$ RMSEA $=.06,10=.00$, $\mathrm{hi}=.10 ; \mathrm{CFI}=.94)$. Initial analyses revealed that social networking did not predict any of the main variables; accordingly social networking was dropped in the final model. Further, our initial model suggested that blogging was not predictive of perceptions of social support ( $\beta=.09, \mathrm{~ns})$, thus we also dropped this structural path in the final model. Figure 2 shows the final model with standardized path estimates for all participants as a whole. The final model fit the data well $\left(\chi^{2}(12)=10.63, P=.56\right.$; RMSEA $=.00$, lo $=.00$, hi $=.07 ;$ CFI $=.99$ ). Frequency of blogging predicted greater feelings of connection with extended family and friends $(\beta=.25, P<.01)$. Connection predicted greater perceptions of social support $(\beta=.36, P<.001)$, and increased social support predicted decreased parenting stress $(\beta=-.19, P<.05)$ and marital conflict $(\beta=-.33, P<.001)$, and increased marital satisfaction $(\beta=.26, P<.001)$. Surprisingly, social support was not predictive of maternal depression $(\beta=-.13$, ns). Finally, decreased parenting stress predicted decreased maternal depression $(\beta=.24, \quad P<.01)$ and marital
Fig. 2 Final model of media influence on maternal wellbeing. $* P<.05, * * P<.01$, $* * * P<.001, \mathrm{~N}=146$

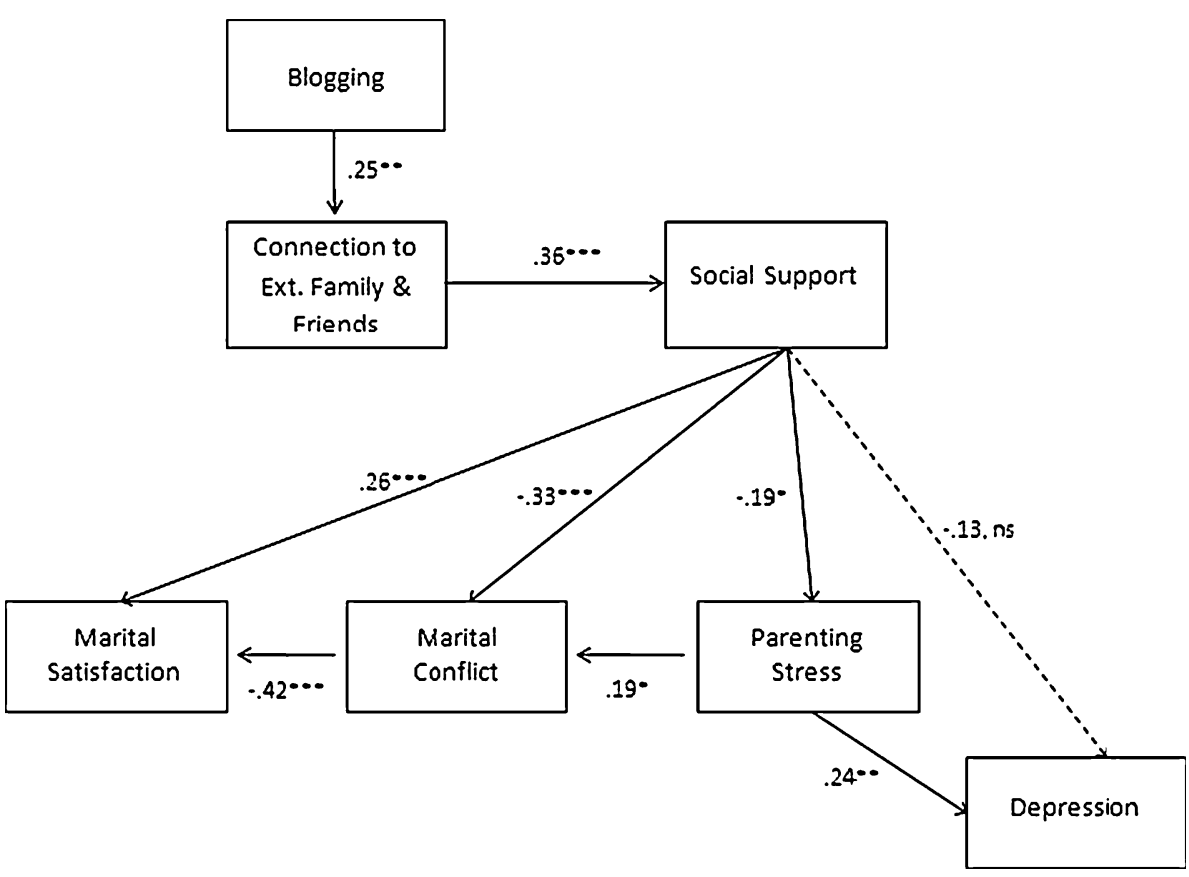


conflict $(\beta=.19, P<.05)$, and decreased marital conflict was strongly predictive of increased marital satisfaction $(\beta=-.42, P<.001)$.

\section{Discussion}

To our knowledge, this paper is one of the first to examine first-time, new mothers' social media use, especially blogging and social networking, and the potential relationship between media use and maternal well-being. According to our results, new mothers appear to be on the computer around 3 hours per day (mostly on the Internet) - a significant proportion of time. It may be that some of this time is while mothers are at work, but only half of the mothers in this sample were currently working. More importantly, during this time, new mothers frequently use social networking sites and sometimes blogs.

Our results revealed that frequency of blogging positively predicted feelings of connection to extended family and friends. This could potentially be a result of new mothers' intentions in their blogging. Whereas in a recent survey of bloggers, $37 \%$ blogged in order to stay in touch with friends and family [31], the majority of new mothers in our sample stated this as their major reason for blogging $(86 \%)$. This is similar to previous findings that expression and affiliation explain most of the reasons people use blogs [42], and media tends to help mothers stay in touch with others [43].

New mothers' interactions with extended family members and friends through their blogging (i.e., the mesosystem) theoretically influence their feelings of connection and social support, as well as interactions within their microsystems (i.e., parenting stress, marital satisfaction, conflict, and depression). Bronfenbrenner's ecological theory would posit that as mothers are able to share successful parenting experiences on blogs, receive feedback from family and friends, and also learn through vicarious experience while reading blogs, their perceptions of social support could increase. Our analyses provide initial empirical support for these claims. Future research may also wish to examine exosystem and macrosystem processes.

Thus, blogging is indirectly associated with other areas of a mother's life through feelings of connection and support. In their review, Gjerdingen, Froberg, and Fontaine found that social support across the transition to parenthood-in many forms, such as emotional, tangible, and informational-was positively related to maternal wellbeing and mental health [44]. Social support has consistently been linked to diminished maternal depressive symptoms [27, 45, 46], as well as better marital functioning [8]; both of these associations were observed in this study.
Although there was not a direct effect of perceptions of social support on new mothers' depression, parenting stress did appear to act as an intervening variable between social support and depression. In sum, blogging may improve new mothers' well-being, as they feel more connected to the world outside their home through the Internet [20, 43].

Conversely, unlike blogging, our results revealed that social networking was not associated with connectedness or social support. Thus, it appears that social networking functions somewhat differently than blogging. Perhaps new mothers may use these sites to see what friends and family are up to in their lives, looking at pictures and status updates, but may not receive much support in return. Accordingly, they do not feel more connected or supported by those important to them, nor do others build their feelings of competence as a parent. We did not analyze such possibilities in the current research; accordingly this represents one useful avenue for future research.

There are also privacy concerns with social networking sites, such as MySpace and Facebook [47], and although Dwyer, Hiltz, and Passerini found that individuals are likely to disclose most information regardless of trust [48], this process may work differently for mothers; if a mother feels that she cannot trust the site she may be less likely to disclose parenting concerns and calls for support. For instance, Mital, Israel, and Agarwal found that trust mediated disclosure of information at least partially for their sample [49]. Future research should examine how and with whom new mothers interact on social networking sites.

\section{Limitations and Future Directions}

This study, although informative and a necessary first step to understanding social media effects on new mothers, is exploratory in nature. As is the case in any correlational research, we cannot establish causation. Further, demonstrated effects may be reversed; for example, it may be that those mothers with stronger relationships tend to turn to blogging more to connect with extended family and friends. It is also possible that those with better well-being may be more or less likely to use media for social support. Even if this were the case, we hypothesize that blogging or reaching out to extended family and friends would reciprocally increase their perceptions of social support, and social support has been linked by prior research to a variety of maternal well-being outcomes [7-9, 50-53]. Our sample was limited and consisted of mostly white, highly-educated mothers. It is also important to note that blogging can be done in different domains. For example, some mothers may blog in order to connect with family and friends, while others may blog in order to connect with other parents on the web. This study did not address this distinction. Finally, our measures of media use were limited (e.g., access to 
social media supports on the Internet via mobile phones and other devices was not examined).

There are a number of other directions that may be profitable for future research. As this study did not have a comparison group of women, future research may wish to compare both mothers and non-mothers on their media use. Also, it may be of worth to understand exactly which social networking and parenting sites mothers use most frequently in order for health professionals to best reach out to mothers on the Internet. Finally, it would be important to understand whether those who live farther away from parents and extended family are more likely to blog; blogging may be more beneficial for those who are unable to visit in-person with extended family.

\section{Conclusion and Practical Implications}

Research on mothers' media use is still in its infancy; therefore an exploratory study was necessary. The current study acts as a springboard for the development of larger scale projects and theoretical models for media influences on new mothers across the transition to parenthood. New mothers appear to be immersed in new age media, such as blogging and social networking. This study shows that new mothers' blogging is associated with feelings of connection to extended family and friends. These feelings link with perceptions of social support, which are related to many aspects of maternal well-being, such as marital conflict, marital satisfaction, parenting stress, and finally depression. As blogging is a relatively simple task and small associations were found even for those who blogged only sometimes, doctors, clinicians, and family life educators may wish to mention blogging as one way for new mothers to feel more connected to extended family and friends.

\section{References}

1. Perren, S., Von Wyl, A., Burgin, D., Simoni, H., \& Von Klitzing, K. (2005). Depressive symptoms and psychosocial stress across the transition to parenthood: Associations with parental psychopathology and child difficulty. Journal of Psychosomatic Obstetrics and Gynecology, 26(3), 173-183.

2. Leigh, B., \& Milgrom, J. (2008). Risk factors for antenatal depression, postnatal depression and parenting stress. BMC Psychiatry, 8, 24-35.

3. Lawrence, E., Rothman, A., Cobb, R., Rothman, M., \& Bradbury, T. (2008). Marital satisfaction across the transition to parenthood. Journal of Family Psychology, 22, 41-50.

4. Beck, A. N., Cooper, C. E., McLanahan, S., \& Brooks-Gunn, J. (2010). Partnership transitions and maternal parenting. Journal of Marriage and Family, 72, 219-233.

5. Mistry, R. S., Vandewater, E. A., Huston, A. C., \& McLoyd, V. C. (2002). Economic well-being and children's social adjustment:
The role of family process in an ethnically diverse low-income sample. Child Development, 73, 935-951.

6. Cooper, C. E., McLanahan, S. S., Meadows, S. O., \& BrooksGunn, J. (2009). Family structure transitions and maternal parenting stress. Journal of Marriage and Family, 71, 558-574.

7. Meadows, S. (2011). The association between perceptions of social support and maternal mental health: A cumulative perspective. Journal of Family Issues, 32, 181-208.

8. Salmela-Aro, K., Nurmi, J.-E., Saisto, T., \& Halmesmaki, E. (2010). Spousal support for personal goals and relationship satisfaction among women during the transition to parenthood. International Journal of Behavioral Development, 34, 229-237.

9. Crnic, K. A., Greenberg, M. T., Robinson, N. M., \& Ragozin, A. S. (1984). Maternal stress and social support: Effects on the mother-infant relationship from birth to eighteen months. American Journal of Orthopsychiatry, 54, 224-235.

10. Rideout, V. J., Foeher, U. G., \& Roberts, D. F. (2010). Generation $\mathrm{M}^{2}$ : Media in the lives of 8- to 18-year-olds. Kaiser Family Foundation. Accessed online March 8, 2011. http://www.kff. org/entmedia/upload/8010.pdf.

11. Hall, W., \& Irvine, V. (2009). E-communication among mothers of infants and toddlers in a community-based cohort: A content analysis. Journal of Advanced Nursing, 65, 175-183.

12. Miyata, K. (2002). Social support for Japanese mothers online and offline. In B. Wellman \& C. Haythornthwaite (Eds.), The internet in everyday life. Malden, MA: Blackwell.

13. Sutton, J., \& Pollock, S. (2000). Online activism for women's rights. Cyberpsychology and Behavior, 3, 699-706.

14. Youngs, G. (2001). Theoretical reflections on networking in practice: The case of the women on the net. In E. Green \& A. Adam (Eds.), Virtual gender: Technology, consumption and identity (pp. 84-99). London: Routledge.

15. Pitts, V. (2004). Illness and internet empowerment: Writing and reading breast cancer in cyberspace. Health, 8, 33-59.

16. Nie, N., Hillygus, H. D. S., \& Erbring, L. (2002). Internet use, interpersonal relations, and sociability. In B. Wellman \& C. Haythornthwaite (Eds.), The internet in everyday life. Malden, MA: Blackwell.

17. Di Maggio, P., Hargittai, E., Neumann, W. R., \& Robinson, J. P. (2001). Social implications of the internet. Annual Review of Sociology, 27, 307-336.

18. Cochran, L. (2011, Feb 23). Queen of the mommy bloggers. New York Times. Accessed online March 8, 2011. http://www.nytimes. com/2011/02/27/magazine/27armstrong-t.html?_r=1\&adxnnl=1\& adxnnlx=1299611015-19fELjjfcKM+rFVYxwX9tA.

19. Feinberg, J. (2010, May 4). Modern moms connect by writing and reading blogs. The Patriot Ledger. Accessed online March 8, 2011. http://www.patriotledger.com/lifestyle/x1042479950/Modernmoms-connect-by-writing-and-reading-blogs\#axzz1G2LkXadM.

20. Madge, C., \& O'Connor, H. (2006). Parenting gone wired: Empowerment of new mothers on the internet? Social and Cultural Geography, 7, 199-220.

21. Plantin, L., \& Daneback, K. (2009). Parenthood, information and support on the internet. A literature review of research on parents and professionals online. Family Practice, 10, 1-12.

22. Lavee, Y., Sharlin, S., \& Katz, R. (1996). The effect of parenting stress on marital quality. Journal of Family Issues, 17, 114-135.

23. Mystry, R., Stevens, G. D., Sareen, H., De Vogli, R., \& Halfon, N. (2007). Parenting-related stressors and self-reported mental health of mothers with young children. American Journal of Public Health, 97, 1-8.

24. Coltrane, S. (2000). Research on household labor: Modeling and measuring the social embeddedness of routine family work. Journal of Marriage and the Family, 62, 1208-1233.

25. Vessey, J., \& Knauth, D. (2001). Marital change during the transition to parenthood. Pediatric Nursing, 27, 169. 
26. Coleman, P. K., \& Karraker, K. H. (1998). Self-efficacy and parenting quality: Findings and future applications. Developmental Review, 18, 47-85.

27. Leahy-Warren, P., McCarthy, G., \& Corcoran, P. (2011). Firsttime mothers: Social support, maternal parental self-efficacy and postnatal depression. Journal of Clinical Nursing. doi:10.1111/j. 1365-2702.2011.03701.x.

28. Raikes, H., \& Thompson, R. (2005). Efficacy and social support as predictors of parenting stress among families in poverty. Mental Health Journal, 26, 177-190.

29. Bronfenbrenner, U. (1986). Ecology of the family as a context for human development. Developmental Psychology, 22, 723-742.

30. Harcourt, W. (2000). The personal and political: Women using the internet. Cyberpsychology and Behavior, 3, 699-706.

31. Lenhart, A., \& Fox, S. (2006). A portrait of the internet's new storytellers (pp. 1-33). Pew Internet \& American Life Project. Accessed online March 8, 2011. http://www.pewinternet.org.

32. Marshall, N. L., \& Barnett, R. C. (1993). Work-family strains and gains among two-earner couples. Journal of Community Psychology, 21, 64-78.

33. Weiss, R. (1974). The provisions of social relationships. In Z. Rubin (Ed.), Doing unto others. Englewood Cliffs, NJ: Prentice-Hall.

34. Abidin, R. R. (1983). Parenting stress index manual. Charlottesville, VA: Pediatric Psychology Press.

35. Busby, D. M., Holman, T. B., \& Taniguchi, N. (2001). RELATE: Relationship evaluation of the individual, family, cultural, and couple contexts. Family Relations, 50, 308-316.

36. Norton, R. (1983). Measuring marital quality: A critical look at the dependent variable. Journal of Marriage and Family, 45, 141-151.

37. Radloff, L. S. (1977). The CES-D scale: A self-report depression scale for research in the general population. Applied Psychological Measurement, 1, 385-401.

38. Arbuckle, J. L., \& Wothke, W. (1999). Amos 4.0 user's guide. Chicago: Small Waters

39. Buhi, E. R., Goodson, P., \& Neilands, T. B. (2007). Structural equation modeling: A primer for health behavior researchers. American Journal of Health Behavior, 31, 74-85.

40. Hu, L., \& Bentler, P. M. (1999). Cutoff criteria for fit indexes in covariance structure analysis: Conventional criteria versus new alternatives. Structural Equation Modeling, 6, 1-55.
41. Kline, R. B. (2011). Principles and practice of structural equation modeling (3rd ed.). New York: Guilford Press.

42. Kaye, B. K. (2005). It's a blog, blog, blog, blog world. School of Journalism \& Electronic Media, 13, 73-95.

43. Descartes, L., \& Kottak, C. P. (2009). Media and middle class moms: Images and realities of work and family. New York: Routledge.

44. Gjerdingen, D. K., Froberg, D. G., \& Fontaine, P. (1991). The effects of social support on women's health during pregnancy, labor and delivery, and the postpartum period. Family Medicine, 23, 370-375.

45. Dennis, C., \& Letourneau, N. (2007). Global and relationshipspecific perceptions of support and the development of postpartum depressive symptomatology. Social Psychiatry and Psychiatric Epidemiology, 42, 389-395.

46. Howell, E. A., Mora, P., \& Leventhal, H. (2006). Correlates of early postpartum depressive symptoms. Maternal and Child Health Journal, 10, 149-157.

47. Gross, R., \& Acquisti, A. (2005). Information revelation and privacy in online social networks. In Proceedings of WPES'05 (pp. 71-80). Alexandria, VA: ACM.

48. Dwyer, C., Hiltz, S. R., \& Passerini, K. (2007). Trust and privacy concern within social networking sites: A comparison of Facebook and MySpace. In Proceedings of AMCIS. Accessed online April 6, 2011. http://aisel.aisnet.org/amcis2007/339.

49. Mital, M., Israel, D., \& Agarwal, S. (2010). Information exchange and information disclosure in social networking web sites: Mediating role of trust. Learning Organization, 17, 479-490.

50. Crnic, K. A., \& Booth, C. L. (1991). Mothers' and fathers' perceptions of daily hassles of parenting across early childhood. Journal of Marriage and Family, 53, 1042-1050.

51. Balaji, A. B., Claussen, A. H., Smith, D. C., Visser, S. N., Morales, M. J., \& Perou, R. (2007). Social support networks and maternal mental health and well-being. Journal of Women's Health, 16, 1386-1396.

52. Bost, K. K., Cox, M. J., Burchinal, M. R., \& Payne, C. (2002). Structural and supportive changes in couples' family and friendship networks across the transition to parenthood. Journal of Marriage and Family, 64, 517-531.

53. Crnic, K. A., Greenberg, M. T., Ragozin, A. S., Robinson, N. M., \& Basham, R. B. (1983). Effects of stress and social support on mothers and premature and full-term infants. Child Development, 54, 209-217. 